\title{
Employment Creation Through Small, Medium and Micro Enterprises (SMMEs) in South Africa: Challenges, Progress and Sustainability
}

\author{
Edwin Mwasakidzeni Mutyenyoka
}

edwinmutyenyoka@gmail.com

\author{
Thanyani S Madzivhandila
}

University of Limpopo, Faculty of Management and Law, Department of Planning and Management

Private Bag X1106, Sovenga, 0727, South Africa

tmadzivhandila@gmail.com

\section{Doi:10.5901/mjss.2014.v5n25p65}

\begin{abstract}
South Africa is characterized by the persistence of structural and cyclical unemployment which manifests in $24,7 \%$ of the country's working-age enduring long term joblessness. This socio-economic plight has engendered the promotion of Small, Micro and Medium Enterprises (SMMEs) as instrumental vehicles for employment creation despite formidable challenges they face. As much as the SMME sector absorbs the majority of total labour force, their failure to resist internal and external shocks restricts growth and graduation into the formal sector. SMMEs are renowned for short lifespans, poverty wages and precarious employment opportunities suggesting they fail to lift the boards. It is against this backdrop that this paper concludes that, it is imperative to, firstly, increase financial and non-financial support, sector-specific research and the design of customized interventions as well as reducing regulatory constraints on SMMEs in order for the small businesses to survive, grow and create sustainable employment for the discouraged South African labour force. The purpose of this paper is to expose the South African employment challenge, trace SMME progress (or lack thereof) in employment creation, identify constraints faced by small entities and present recommendations as, perhaps a way forward for the exacerbation of small entity productivity, improvement of earnings of the working poor and getting the poor working.
\end{abstract}

Keywords: SMMEs; Unemployment; Labour Force, South Africa

\section{Introduction}

The persistence of poverty, inequality and high unemployment rates has invariably haunted developing countries such as South Africa. Long term structural and cyclical unemployment are common despondent conditions endured by the South African labour force, even more so in the post-Apartheid era. Around 24, 7\% of the country's working-age (16 - 64 years) is unemployed (Statistics South Africa (StatsSA), 2014). This socio-economic plight has engendered the prioritization and promotion of counter economic sectors including agriculture, energy, manufacturing, mining and Small, Micro and Medium Enterprises (SMMEs). This paper will focus on the latter. Although there is no internationally agreed-upon criterion on what constitutes SMMEs as definitions differ according to the number of employees, annual turnover and industry type, the key rationale for their development is that SMMEs are ordinarily viewed as essential vehicles for employment creation. Providentially, the newly established Ministry of Small Businesses and Entrepreneurship in South Africa timely emerged as testimony to government's acknowledgement of the SMMEs sector as a critical piece to the country's economic puzzle and unemployment woes (Republic of South Africa (RSA), 2014). Currently, the SMME sector absorbs $72 \%$ of the total labour force in South Africa, despite formidable challenges (Department of Trade and Industry (DTI), 2014).

In as much as this sector absorbs a majority of the total labour force in the country, varying internal and external challenges elicit the collapse of over $75 \%$ of new and established enterprises. Small entities struggle to graduate from the 'baby business' phase and eventually succumb to economic shocks within the first few months of establishment (Global Entrepreneurship Monitor (GEM), 2013). Subsequently, the poor performance of SMMEs places the labour force (of which the majority is unskilled) tied to the SMMEs sector in a precarious employment position. Moreover, the reputation of the Medium Enterprise cluster as the "employment bandwagon" boarded by the uneducated, illiterate and unskilled labour force repelled from the formal job market continues to drastically deteriorate due to the competitiveness of global 
markets which requires optimum productivity and highly skilled human resource (Ntsika, 1999; DTI, 2012). Furthermore, according to the 2013 Statistics South Africa Quarterly Labour Force and Household Survey 46\% of the labour force (of the $72 \%$ employed by SMMEs) earns less than the poverty line (R1200), suggesting that small business have failed to lift the boards (StasSA, 2013). It is against this background that this paper argues that, the mandate of SMMEs has surpassed the quest to merely create jobs but rather to strike equilibrium between improving the earnings of the working poor and to get the poor working by firstly increasing financial and non-financial support, the design of customized training curriculums and sector-specific research on regulatory constraints on the small entities. This paper will conceptualize the employment problem in South Africa, trace and evaluate progress, or lack thereof, made by the SMME sector not only in creating employment but 'good' employment, identify challenges that impede SMMEs from optimum labour force absorption, design recommendations for entrepreneurs, job seekers and, perhaps the newly established Ministry of Small Businesses and Entrepreneurship and also to identify research gaps for further analysis.

\section{South Africa's Employment Challenge}

It is well known that South Africa suffers from a persistent unemployment problem (Amra et al., 2013). Broadly, the unemployed are those who did not work in the last seven days but were available to work and actively looked for a job. The most perpetual dimensions of South Africa's unemployment challenge have been found to be structural and cyclical unemployment. These two prevalent types to unemployment respectively refer to a mis-match between jobs available and the level of skills of jobseekers (structural) and the loss of jobs (cyclical), due to either retrenchment or forces of recession (Amadeo, 2014). While technology and other business dynamics compound structural employment, regular global economic recessions continually force South African labour force into cyclical unemployment. On one hand, the STATSSA Quarterly Labour Force Survey (2013) recorded that unemployment is generally higher among the low skilled, uneducated, youths and women. On the other, the DTI (2013) reports that, in the formal economy and within large enterprises, a person with more skills and educational qualifications stands better chances of employment than the one with lesser. Meanwhile, unemployment levels are higher among women $(27.8 \%)$ than their male $(21.3 \%)$ counterparts, despite year on year percentage decreases in unemployed women $(-1,9 \%)$ have been higher than in men $(-0,6 \%)$, signalling an optimistic projection on equitable redistribution of employment opportunities between genders in South Africa (StatsSA, 2014).

The employment challenge goes beyond unemployment to encompass those with very low hourly wages, those with inadequate monthly or yearly work hours, and those who have to work too long hours just to be able to eke out a meager livelihood. Twenty years into democracy, the South African unemployment rate still hoovers in the regions of $25 \%$ (StatsSA, 2014). Moreover, according to the October Household Survey by Statistics South Africa (2013), 46\% of the employed labour force (7million) earn less than the poverty line (R1 200 per month), provoking a longstanding dilemma in South African literature about whether to maintain lower wages in order to create more jobs or to improve earnings and maintain fewer workers (Fields, 2000 and Amra et al., 2013). Therefore, as high as unemployment numbers are, it is as imperative to focus on the unemployed as it is to elevate the earning of the working poor.

\section{SMME Progress (or Lack Thereof) in Employment Creation}

Over the years, the South African government has employed a series of policies in continual pursuit of equilibrium between increased job opportunities, improved wages and gender equality through education, skills development and training on the supply side of sustainable employment. On the demand side there have been the expansion of public works (Expanded Public Works Programme(EPWP)), investment in public infrastructure, Black Economic Empowerment (BEE) and perhaps more importantly to this paper, policies to promote SMMEs (Amra et al., 2013; RSA, 2014). There is, therefore, need to trace the evolution of the SMME sector, the progress, or lack thereof, made in creating not only employment but sustainable and equitable employment opportunities for the discouraged South African labour force.

\subsection{The evolution of the SMME sector in South Africa}

The promulgation of the 1996 White Paper on Small Businesses into Act marked a constitutional mandate and recognition of SMMEs as major players in the South African economy in resolving unemployment and other socioeconomic woes inherited from the Apartheid era (RSA, 1998; Rogerson, 2010). Through the Integrated Small Business Development Strategy, the government then introduced financial and non-financial support systems such as Small Enterprise Development Agency (SEDA), Ntsika Enterprise Promotion Agency, Khula Enterprise Finance and the Center 
for Small Business Promotion (CSBP) to nurture and enhance growth and sustainability for the small entities in all provinces (DTI, 2008; Khula, 2008); Dlovi 2012). SMMEs continued to attain remarkable attention leading to their inclusion as one of the main focal points in the National Development Plan (NDP) due to their labour absorptive capacity in times of a shrinking public sector and private formal economy, economic downturns (recession) and increasing numbers of new labour entrants. The pinnacle of the evolution of the SMME economy in South Africa, thus far, was the recent establishment of The Ministry of Small Businesses and Entrepreneurship in 2014 under Honorable Minister Lindiwe Zulu who declared on her appointment ceremony, that '... government recognizes small businesses as major players in job creation and the economy.' The new ministry, thus, emerged to carry hopes and expectations of masses of aspirant, survivalist and established entrepreneurs and job seekers who expectantly await for the transformation of policies and structures linked to the SMME sector in pursuit of optimum productivity of small entities, increment of the earnings of those employed in SMMEs whilst creating sustainable opportunities for the discouraged labour force.

\subsection{Labour force absorption capacity of SMMEs}

According to Amra et al. (2013) and Rogerson (2008) SMMEs hold the leading role in the resolve of the persistence of insufficient employment growth in South Africa. The Department of Trade and Industry (2008) and StasSA Quarterly Labour Force Survey (2014) confirm that the SMME economy accounts for more than 35\% of Gross Domestic Product (GDP) and approximately $72 \%$ of all jobs in the country. These figures add to unique capabilities possessed by SMMEs in the creation of employment opportunities especially for the victims of structural unemployment, thus the uneducated, unskilled, youth and women who form the majority of the labour force. The 2013 Global Entrepreneurship Monitor Survey highlights that in 2012 South Africa had around 6million small businesses of which 60\% of both the owners and workers had neither a matric certificate nor any substantial qualification (DTI, 2008; World Bank, 2012d). With close to 55\% of the total South African labour force falling under the 'unskilled and semi-skilled' bracket, the contribution of SMMEs in absorbing victims of structural unemployment cannot be underestimated, meanwhile the mounting attention received by the sector from South African policy-makers continues to gain credibility and justification.

In light of the preceding discussion, SMMEs are also seen as gateway opportunities for the discouraged labour force to escape from long term unemployment, which emanates from gender discrimination, in some instances. Both anecdotal and factual evidence suggests that the prominence of gender-biased unemployment implies that women stand lesser chances of securing and keeping jobs than their male counterparts in larger firms and the formal economy. According to the Labour Force Survey, unemployed women are 6, 6\% more than men, on one hand (StatsSA, 2013). On another, the Global Entrepreneurship Survey reported that $58 \%$ of the 6million small businesses in South Africa are owned by women (World Bank GEM, 2013). There is a positive correlation between volumes of females rejected from the formal labour market and new female entrepreneurs in the informal sector (Winks, 2008; Ladzani \& Netswera, 2009). One might then deduce that the influx of women into entrepreneurship and small businesses is neither a coincidence nor planned exploitation of market opportunities but rather a gateway from long term structural and cyclical unemployment and gender based discrimination in the formal labour market/economy.

Rampant influx of surplus labour into already congested city centres has been attributed to poor labour force absorption capacity by the rural economy (Skinner, 2005). Off late, urban planners have reactively advocated for the support and development of rural businesses as panacea to the moderation of rapid urbanization. A win-win scenario for migrant jobseekers, 'city fathers' and rural economies would be attained when socio-economic, especially employment, opportunities are decentralized from provincial economic hubs to rural growth points and nodes. Long term and sustainable solutions to poor labour force absorption by the rural economy is dependent on infrastructure-driven Local Economic Development (LED), the provision of credit backed by proper training in managerial skills. Thus, the probability of SMMEs to reach their potential in the creation of employment and curtailing mass exodus of rural surplus work force into urban fringes and informal settlements is as difficult to measure as progress in rural development itself. Small enterprises in remote areas typically consist of general dealers and spaza shops, which compete with one another for a limited clientele, as well as with larger shops in the local centres. The returns from these enterprises are considered to be precarious, given the pervasive poverty, unemployment and the resultant weak buying power of rural dwellers (Mbhele and Aliber, 2005).

In other instances, commercialized technologies have prompted small and medium entrepreneurs to transmit the burden of unstable markets to their employees and to base competition on squeezing labour costs rather than paying for commercialized technological upgrades. However, the competitive nature of the global economy requires optimum productivity, which implies that medium enterprises are restricted from accommodating hordes of unskilled labour force in their operations and the trend, understandably, engenders deliberate absorption of trained, skilled, educated and 
experienced work force. It is against such a background that the capacity of SMMEs to continually tolerate discouraged and disadvantaged groups of the labour force, regardless of insurmountable challenges they face, is laudable.

\section{Challenges Faced by SMMEs}

The capacity of SMMEs to amass profits, grow, employ and retain employees is inextricably linked to their ability to resist a variety of formidable challenges they encounter in the internal and external environment. Principle challenges haunting South African SMMEs will be elaborated under this section.

Chief among many problems which SMMEs often face is the lack of financial resources. Access to adequate capital allows small businesses to investments into inventory, technology, and training in order to propel entity productivity, growth and the subsequent need for more human resources, thus employment growth (Hess \& Rust, 2010). Notwithstanding the availability and functionality of financial aid institutions such as, Khula Enterprise Finance and South African Microfinance Apex Fund (SAMAF), which are specifically established to serve financial needs of small businesses, SMMEs development is still constrained by the limited access to financial resources to meet a variety of operational and investment needs. Various studies found that over $90 \%$ of small enterprises in different cities around South Africa identified poor access to credit as a major constraint (Fatoki, 2011; Peters, 2012; World Bank, 2012d). For example, both the Johannesburg and Durban surveys of SMMEs which were conducted by the World Bank funded Global Entrepreneurship Survey pinpointed the lack and poor access to credit as the core business constraint faced by, especially, emerging SMME entrepreneurs. A study by the USAID (2008:18) further revealed that, 'the debt check by lending institutions prior to granting loans thereby uncovering the extent of borrowing was considered a hindrance to accessing finance, survival and growth.' Meanwhile, issues of poor access and high interest rates are underpinnings of low usage of formal bank loans, exacerbated by complex application processes, lack of collateral and credit history, the most prevalent source of business start-up capital are personal savings or borrowing from friends and relatives. Only $2 \%$ of the 200 surveyed small business owners in Gauteng reported use loans (FinMark Trust, 2006b). A combination of the mentioned and other internal, institutional and external variables represents formidable challenges that SMMEs encounter in acquiring the financial resources needed to operate on a solid footing, grow and increase human resource (employment growth).

Whilst King et al (2002), DTI (2008) and Amra et al. (2013) consistently pointed to the lack of managerial skills and training as the root cause for poor SMME performance in the local economy, trends in the global economy raise the bar and essence of what has been termed "learning-led competitiveness" even higher. To respond to the challenge of competitiveness, entrepreneurs are obliged to devise strategies aimed at improving individual employees' and their own level of business knowledge and skills. The role of training and skills development is thus seen as essential for, especially, emerging SMME enterprises in order for them to 'learn to grow'. The intrinsic nature of training and skills development for the emerging and small scale entrepreneurs was exposed by findings of, among others, the Business Monitor International Survey (BMI) and the Gauteng Enterprise Propeller (GEP) which estimated that an average of 80\% of the collapsed entities in 2013 in Johannesburg and Pretoria were owned and managed by non-matric holders (Skinner 2005; Rogerson, 2008, Amra et al., 2013). It is thereby not coincidental that the most successful, innovative and more labour absorptive small businesses are those that are run by educated and skilled owners and personnel.

Despite the well documented significance of training and skills, $90 \%$ of a sample of 100 small business entrepreneurs dismissed or saw little need for skills training in a study taken by the Global Entrepreneurship Monitor in Polokwane City (Fatoki, 2012; World Bank 2012d). This further confirmed that small business entrepreneurs do not appreciate the link between training and business improvement. Yet, the Stats SA Integrated Business Register records an average annual failure rate as high as 75\% in SMMEs (DTI, 2008). Having mentioned that, it should be cautioned that, ignorance about management skills and training are neither the only nor the main .culprit for the failure of small businesses in South Africa. This is so because, in some instances, small businesses, understandably, cannot afford the high cost of training and advisory services considering their already strained cash flows and budgets. Moreover, the mentioned SMME plights and others, are evidence of the failure of two-decade-old government programmes in encouraging and designing sector specific training curriculums for SMMEs through, for example, the Skills Training and Educational Authority (SETA) and the Education Training and Development (ETD) (Peters, 2012). However, the newly established Ministry of Small Businesses and Entrepreneurship is expected and recommended to holistically and deliberately police the extension of knowledge and skills beyond corporate and the formal sector towards the previously disadvantaged groups (women and non-white races) and informal businesses which form the majority in the economy.

Rogerson (2012) further identified a set of probable reasons for the poor economic and labour absorption performance by SMMEs in their respective industries (manufacturing, retail or service). In his study he concluded that, 
SMMEs compete with large firms instead of complementing them by utilizing their shorter decision making hierarchy and flexibility to produce specialized and unique goods and services that are not produced by red-taped larger firms. This gap and competition between small and large entities is attributed to disparities associated with the dual nature of the South African economy (primary and secondary). A study conducted by the Department of Trade and Industry (2012) on SMMEs in KwaZulu Natal found that, on the very few instances when large firms engage or 'partner' with smaller firms, they tend to seek reduction of costs by exploiting surplus cheap labour conditions and circumventing regulations and trade union organization. Ideally, large firms should act as catalysts for growth to their smaller 'partners' through cooperate subcontracts with small and informal firms. There is dire need for the new Ministry to enhance the shift from an exploitative and competitive relationship between small and large organization towards more partnership and professional harmony if SMMEs are to survive, grow and provide substantial and sustainable employment

The Integrated Small Business Strategy (2005) confirmed that the SMMEs environment is 'over-regulated' and that the regulatory climate discouraged the development of new entities and acted as a barrier to large, energetic and entrepreneurial group of, especially, poor and rural black South Africans from graduating into the formal economy. Regulators have been accused of creating significant efficiency costs, time constraints and red tapes for aspiring and established entrepreneurs instead of embracing the spirit of Local Economic Development (LED) which advocates for the creation of conducive environments for the informal and small scale business (SBP, 2005)It takes at least 126 days and 16 procedures to process some compulsory licenses required to start up a business entity in South Africa (Chamberlain \& Smith, 2006; World Bank, 2010; Amra et al., 20013). Despite, structural reforms (Business Act of 1991 and the Small Business Act of 1996), made to reverse the economic restrictions imposed by Apartheid and improve the informal and small business sector, prospects for SMME survival and growth remain to be addressed at entity and rural level whilst there remains little reference to the principles of regulatory best practice (Christianson, 2003). However, as much as regulations are significant for long-term development, reducing the burden of regulations is unlikely to result in dramatic development of the SMME market in the short term. Regulations are, thus, more likely to be a catalyst or facilitator of development rather than a driver of growth considering that that drivers will come from improvements in the general economic environment and demand conditions combined with initiatives to empower individuals to start their own businesses.

\section{Way Forward for the SMME-Employment Nexus}

Whilst structural and cyclical unemployment compels the majority of the South African labour force to involuntarily remain tied to the SMME sector, issues of access to finance, training opportunities and an appropriate regulatory environment continue to be high on both the international and local policy agenda for SMME development to revamp the benefits off the sector, including a surge in employment volumes and quality (Kongolo, 2010). With the status quo of SMMEs already well documented, the newly established Ministry of Small Businesses and entrepreneurship could not ask for a better literature database as foundation to the reengineering of policies regulating the troubled and yet indispensable sector in the South African economy. However, the panacea to entangling the SMME-Employment nexus requires tripartite efforts from regulators, entrepreneurs and the labour force in order to ultimately strike equilibrium between entity compliance with regulations, exacerbating entity productivity, and perhaps more importantly, to get the poor working whilst improving the earnings of the working poor. It is thereby, imperative to continuously review the appropriateness and functionality of existing finance, training and regulatory environment for supporting SMMEs prior to highlighting areas that critically need fixing, thus a way forward in the new SMMEs era to be spearheaded by the new Ministry.

As mentioned already, SMMEs are commonly faced by capital constraints impeding ideal financing of investment and operational needs. These disparities have been attributed to, mostly, obstructive terms and conditions tabled by financial institutions, prompting entrepreneurs to rely on friends and/or family as primary sources of start-up finance. These and other financial plights faced by small entrepreneurs are, thereby, expected to inform the new policy makers that entrusting SMME access to loans and credit with profit-oriented private financial institutions ('loan sharks' in some cases), relying on the 'good practice' card and mere encouragement for partnerships with the private sector to drive the delivery of financial support is not pragmatic in a capitalist environment such as the South African economy (Fatoki and Smit, 2011). Instead, the adjustments that could, perhaps, be spearheaded by the newly established Ministry revolving around:

* stimulating the creation of venture-capital funds dedicated to franchising. Venture capital is financial capital provided to early-stage, high-potential, and growth start-up entities.

* government-led SMME financial schemes that commence with a diagnosis of the shortfalls of preceding DTI schemes that have been 'functional' for over two (2) decades without moderating SMMEs financial plights, 
specifically for enterprises that show(ed) great potential to develop.

* establishing the causalities to the fragmentation, failure and the eventual collapse of preceding financing strategies, and the need to enhance better co-ordination of incentive grants that target SMME initiatives, and establish an administration system that links the incentive grants to other financial and non-financial support mechanisms in order to maximise the growth of, especially, survivalist and micro enterprises, informal businesses and rural entities

* holistic policing of the Corporate Social Responsibility (CSR)

* examining the market for pro-poor finance and creating an enabling environment for rural entrepreneurship

* subsidizing specifically for small business startups in order for the SMME sector to be nurtured, to grow and to improve the earnings of its work force without compromising the sector's ability to absorb more jobseekers.

* This tried and tested strategy has borne substantial fruits in successful SMME economies in APEC countries such as China and Singapore and might just be what the energetic South African entrepreneurs need in order to operate on a solid footing, grow and hire more workers.

As much as training has not been unanimously labeled as a direct business-success factor, it has been regularly proven that lack of managerial know-how places significant constraints on SME development (Abor \& Quartey, 2010). As asserted before, the reasons behind poor management skills in South African entrepreneurship revolve around high cost of training and advisory services while a portion of entrepreneurs does not see the need to acquire and upgrade skills due to complacency and limited knowledge. Perhaps it is an epoch for the new Ministry to facilitate the overhaul of the already existent training institutions such as the Skills Training and Educational Authority (SETA) and the Education Training and Development (ETD) to effect the needed change in the managerial field of small entities especially for the previously disadvantaged groups (women, non-white races and rural based entrepreneurs). Of particular importance regarding training is the emphasis on the role of training, understanding learning processes in SMMEs in different sectors and especially of emerging SMMEs, evaluation of impact for SMMEs of government training systems, and the design of sector-specific training curriculums (Peters, 2012). Furthermore, the newly established Ministry of Small Businesses and Entrepreneurship is expected and recommended to holistically and deliberately police the extension of knowledge and skills beyond corporate and the formal sector towards the previously disadvantaged groups, informal businesses and rural based enterprises which form the majority in the economy. Moreover, training and skills development is a proven catalyst to improved productivity and the subsequent need for more human resource, thus employment growth. This paper expects and recommends the newly established Ministry of Small Businesses and Entrepreneurship to:

* holistically and deliberately police the extension of knowledge and skills beyond corporate and the formal sector towards the previously disadvantaged groups, informal businesses and rural based enterprises which form the majority in the economy. Moreover, training and skills development is a proven catalyst to improved productivity and the subsequent need for more human resource, thus employment growth.

* facilitate the overhaul of the already existent training institutions such as the Skills Training and Educational Authority (SETA) and the Education Training and Development (ETD) to effect the needed change in the managerial field of small entities especially for the previously disadvantaged groups (women, non-white races and rural based entrepreneurs).

- emphasize on the role of training, understanding the learning processes in especially emerging SMMEs, evaluation of impact of government training systems on SMMEs, and the design of sector-specific training.

Regulations continue to pose grave challenges to the survival and development of SMMEs and despite regular structural reforms leading to improvements, the prospects of SMME reaching their potential remains to be addressed at entity level. It is mainly due to a set of regulatory red-tapes (registration processes, taxes, licenses) that small businesses are discouraged from graduating from the informal to the formal sector, although the registration of entities is unlikely to drastically effect immediate growth but rather gradually facilitate business development in the long term (Rogerson, 2008). However, regardless of the low rate of return linked to the adherence of regulations, the formalization of entities instantly qualifies them for formal benefits such as government support programmes and legal protection from a wide range of economic menaces and shocks such as recession, inflation or crime (Hess \& Rust, 2010). The impact of the changing regulatory environment for SMMEs, sector-specific research on regulations and analysis of appropriate provincial government and municipal regulations for SMME development are further key research issues for future investigation especially now that there is an entire functional Ministry committed to the exacerbation of entity productivity and employment growth in the SMME sector. This paper, thereby, recommends policy makers to:

* streamline the regulatory environment by engaging with government departments such as SARS and DTI among others, in order to, perhaps reduce the compliance burden for small enterprises in areas such as taxation, licenses and registration. 
* introduce well-designed procedures deliberately aimed at reducing or eliminating impinging and unintended consequences of laws and regulations, especially on micro enterprises, informal enterprises, enterprises owned by non-whites, women and youth.

Firm foundations have already been laid in provinces such as KZN where there already exist functional supportive organizations such as the SMME Support Service Delivery Network. If the mentioned and other constraints are adequately addressed by collective efforts from all stakeholders marshalled by the just established ministry, it is expected that the SMME economy will continue to accelerate economic growth, contribute substantially to increased absorption of marginalised labour force and significantly improve the living standards of the poor.

\section{Conclusion}

This paper joined the SMME-Employment discourse by exposing the South African employment challenge, tracing the SMME progress (or lack thereof) in employment creation, establishing formidable constraints faced by the small entities and a presentation of, perhaps, a foundation for the newly established Ministry of Small Businesses and Entrepreneurship as a way forward towards the exacerbation of small entity productivity, improvement of earnings of the working poor and getting the poor working. The paper has firstly disclosed that the structural and cyclical unemployment plight is not limited to joblessness but rather goes beyond to encompass those 'employed' but with very low hourly wages, those with inadequate monthly or yearly work hours, and those who have to work too long just to be able to eke out a meager livelihood. Secondly, SMMEs earned the mandate of being, to some extent, an antidote to the unemployment plight although formidable challenges continually threaten entity sustainability and that of the jobs they create. Thirdly, the capacity of SMMEs to amass profits, grow, employ and retain employees is inextricably linked to their ability to resist a variety of formidable challenges they encounter in the internal and external environment such as finance, training and skills, regulations and 'unsustainable' competition to mention just but a few. Fourthly, with the advent of a new epoch spearheaded by the newly established Ministry, the design of sector-specific training curriculums and the creation of an enabling regulatory environment, deliberate extension of knowledge and skills to small entrepreneurs and rural areas are, perhaps priority areas in the overhaul process of the SMME sector towards optimum productivity and substantial and equitable employment creation. Lastly, the paper identifies research gaps within the financial, training and regulatory dimensions of the sector which implies that there is vast sector-specific research work to be embarked on prior to policy and strategy formulation by the, once, eagerly anticipated Ministry which, today, carries the hope of aspirant and established entrepreneurs, working poor and multitudes of discouraged labour force. Overally, a structural transformation of the overseeing institution thus the Department of Trade and Industry (DTI) to accommodate the new Ministry of Small Business and Entrepreneurship will require a continual inter-departmental relationship. It is through collaborative and collective efforts between the two Ministries that a smooth transition can be attained. Databases, key personnel, progress, challenges and the prevailing scenarios in the SMME sector all need to be retained and incorporated as a foundation to the epoch of the new era in South African SMME economy.

\section{References}

Abor, J. and Quartey, P. (2010). Issues in SME development in Ghana and South Africa. International Research Journal of Finance and Economics, (39), 1450-2887.

Birch, D.L. (1981). Who creates jobs? The Public Interest, (65), 3 -14.

Department of Trade and Industry (DTI), (2008). Annual review of small business in South Africa. http:/ /www.dti.gov.za/sme. (Accessed20 May 2014).

Dlova, M.R. An investigation into constraints impacting on small micro and medium enterprises (SMMEs) access to finance in Buffalo City Metropolitan Municipality. Diss. Rhodes University, 2012.

Dockel, M (2005). SMMEs: Do they live up to expectation? Management Today, 20(10): 58-61.

Fatoki, O.O. and Smit, A. (2011). Constraints to credit access by new SMEs in South Africa: A Supply-Side Analysis, 5(4): $1413-1425$

Gumede, V. (2004). Export propensities and intensities of small and medium manufacturing enterprises in South Africa. Small Business Economics, 22: 379-389.

Hall, C.M. and Rusher, K. (2004). Entrepreneurial characteristics of the New Zealand bed and breakfast sector in small firms in tourism: International Perspectives, (1): 83-98.

Hess, A. A. and Rust, A. A. (2010). The constraints SMMEs experience whilst attempting to recover skills levies from the W\&RSETA in South Africa. African Journal of Business Management, 4(17): 3691-3696.

Kesper, A. (2001). Failing or not aiming to grow? Manufacturing SMMEs and their contribution to employment growth in South Africa. Urban Forum, 12 (2):171-330.

Kongolo, M. (2010). Job creation versus job shedding and the role of SMEs in economic development. African Journal of Business 
Management, 4(11): 2288-2295

Khula (2008). Khula Annual Report 2007. http:///www.khula.org.za (Accessed 23 July 2014).

Ladzani, W. and Netswera, G. (2009). Support for rural small businesses in Limpopo Province, South Africa. Development Southern Africa, 26(2): 225-239.

Barnes, J., Kaplinsky, R. and Morris, M. (2004). Industrial policy in developing economies: Developing dynamic comparative advantage in the South African automobile sector. Competition and Change, 8(2): 153-172.

Ntsika Enterprise Promotion Agency (NEPA) (2003b). Ntsika local business service centres: success stories. Pretoria: Ntsika Enterprise Promotion Agency

Peters, D. (2012), Sustainable Support for SMMEs. Report for Ntsika Enterprise Promotion Agency. Pretoria. Ntsika Enterprise Promotion Agency.

Polokwane Local Municipality (2010/11) Spatial Development Framework http://www.polokwane.gov.za. (Accessed 24 April 2014)

Amra, R., Hlatswayo, A. and McMillan, L. (2013). SMME employment in South Africa: Economic Society of South Africa, 1 (1): 2-30

Republic of South Africa (1995). White Paper on the National Strategy for the Development and Promotion of Small Business. Pretoria: Government Printer.

Republic of South Africa (1996). National Small Business Act of 1996. Pretoria: Government Printer

Rogerson, C. M. (2006). The market development approach to SMME Development: Implications for Local Government in South Africa. Urban Forum, 17(1): 54-78.

Rogerson, C. M. (2008). Tracking SMME development in South Africa: Issues of finance, training and regulatory environment. Urban Forum, 19: 61-81.

Rogerson, C.M. (2008). SMME Development in South Africa's priority sectors. Report for the Department of Trade and Industry. Tshwane: Department of Trade and Industry.

Rogerson, C.M. (2010). Local economic development in South Africa: strategic challenges. Development Southern Africa Journal, 27(4): 481-495.

Statistics South Africa (Stats SA). Small Business Employment, Quarterly Labor Force Survey Quarter 3, 2013. http://www.statssa.gov. za. (Accessed 20 June 2014).

Statistics South Africa 2013. Quarterly Labour Force Survey <http: //www.statssa.gov.za/publication/ find publication asp>. (Accessed 28 April 2014).

United Nations Development Program (UNDP) (2000). Human Development Report: Human rights and Human Development. New York: Macmillan.

United Nations Development Programme (UNDP) (2003). South Africa Development Report 2003: the Challenge of Sustainable Development in South Africa. London: Oxford University Press.

Winks, S. (2008). Aiding SMMEs in SA: Small business. Enterprise Risk, 2(4): 20-21.

World Bank (2004). Beyond Economic Growth. Washington D.C.: World Bank.

World Bank (2012). Doing Business in a More Transparent World, World Bank: Washington, D.C. 